\title{
Review
}

Journal of Innate

Immunity
J Innate Immun 2012;4:424-436

DOI: $\underline{10.1159 / 000337007}$
Received: December 15, 2011

Accepted after revision: February 2, 2012

Published online: April 4, 2012

\section{Lymph Node Macrophages}

\author{
Elizabeth E. Gray Jason G. Cyster \\ Howard Hughes Medical Institute and Department of Microbiology and Immunology, University of California \\ San Francisco, San Francisco, Calif., USA
}

\section{Key Words}

Antigen presentation · F4/80 - Lymphatic sinus - Mac1 ·

Macrophages - Membrane blebs - Phagocytes .

Sialoadhesin/CD169

\begin{abstract}
Lymph node (LN) macrophages have long been known for their efficient uptake of lymph-borne antigens. A convergence of studies on innate and adaptive immune responses has led to exciting recent advances in understanding their more specialized properties: presenting antigens to B cells, dendritic cells and T cells, producing trophic factors and cytokines, and, remarkably, being permissive for viral infection, a property critical for mounting anti-viral responses. LN macrophages have been traditionally divided into subsets based on their subcapsular sinus and medullary locations. Here, we classify LN macrophages into three subsets: subcapsular sinus macrophages, medullary sinus macrophages and medullary cord macrophages. We review the literature regarding the roles of these cells in innate and adaptive immune responses and requirements for their development. We also discuss challenges associated with their purification as well as the existence of additional heterogeneity among LN macrophages.

Copyright $\odot 2012$ S. Karger AG, Basel
\end{abstract}

\section{Introduction}

Macrophages are classically defined as highly phagocytic cells that internalize and degrade particles and pathogens and release mediators that alert the adaptive immune system to invaders. They are bone marrow derived and many are dependent on colony stimulating factor-1 (CSF1) for their development [1,2]. Although traditionally thought to develop from blood monocytes, recent studies indicate that this may not be the case for all macrophages [3]. All tissues in the body contain macrophages, which frequently take on specialized properties that allow them to support functions uniquely required in their tissue of residence. Thus, lymph node (LN) macrophages are distinct from those found elsewhere in the body and support LN-specific as well as more general immune functions.

Many LN macrophages are directly exposed to lymph fluid. Typically, several afferent lymphatics enter the capsule of a single LN and afferent lymph passes into the narrow subcapsular sinus (SCS) that overlies the lymphocyte-rich cortex (fig. 1). Lymph leaves the LN on the opposite (hilus) side via the efferent lymphatic vessel. The region of the $\mathrm{LN}$ adjacent to the efferent vessel, known as the medulla, contains numerous irregularly shaped and

\section{KARGER \\ Fax +4161306 1234 \\ E-Mail karger@karger.ch}

www.karger.com
(C) 2012 S. Karger AG, Basel

1662-811X/12/0046-0424\$38.00/0

Accessible online at: www.karger.com/jin
Dr. Jason G. Cyster, Howard Hughes Medical Institute and Department of Microbiology and Immunology University of California San Francisco, 513 Parnassus Avenue San Francisco, CA 94143-0414 (USA)

Tel. +1 415502 6427, E-Mail Jason.Cyster@ucsf.edu 
Fig. 1. Schematic of LN showing major zones and lymphatic sinuses and suggested nomenclature for macrophage subsets. Boxed regions are enlarged on the right to show more details. Upper box: SCS and interfollicular region with follicle shown in green shading, $\mathrm{T}$ zone in blue and interfollicular region in purple. Lower box: medullary region in cross-section showing medullary cords in light brown. Sinuses are shown in white and sinus-lining lymphatic endothelial cells are yellow. The macrophages are labeled based on the suggested SSM, MSM and MCM nomenclature discussed in the main text. Their CD169, CD11b and F4/80 phenotype is summarized, although it is not yet established whether the physical segregation of cells with the indicated MSM and MCM marker patterns is as distinct as shown. A DC is shown in dark blue (upper) and a polymorphonuclear cell in brown (lower). Reticular fibers within medullary sinuses are in grey. $\mathrm{B}=\mathrm{B}$ cell; $\mathrm{T}=\mathrm{T}$ cell $; \mathrm{PC}=$ plasma cell.

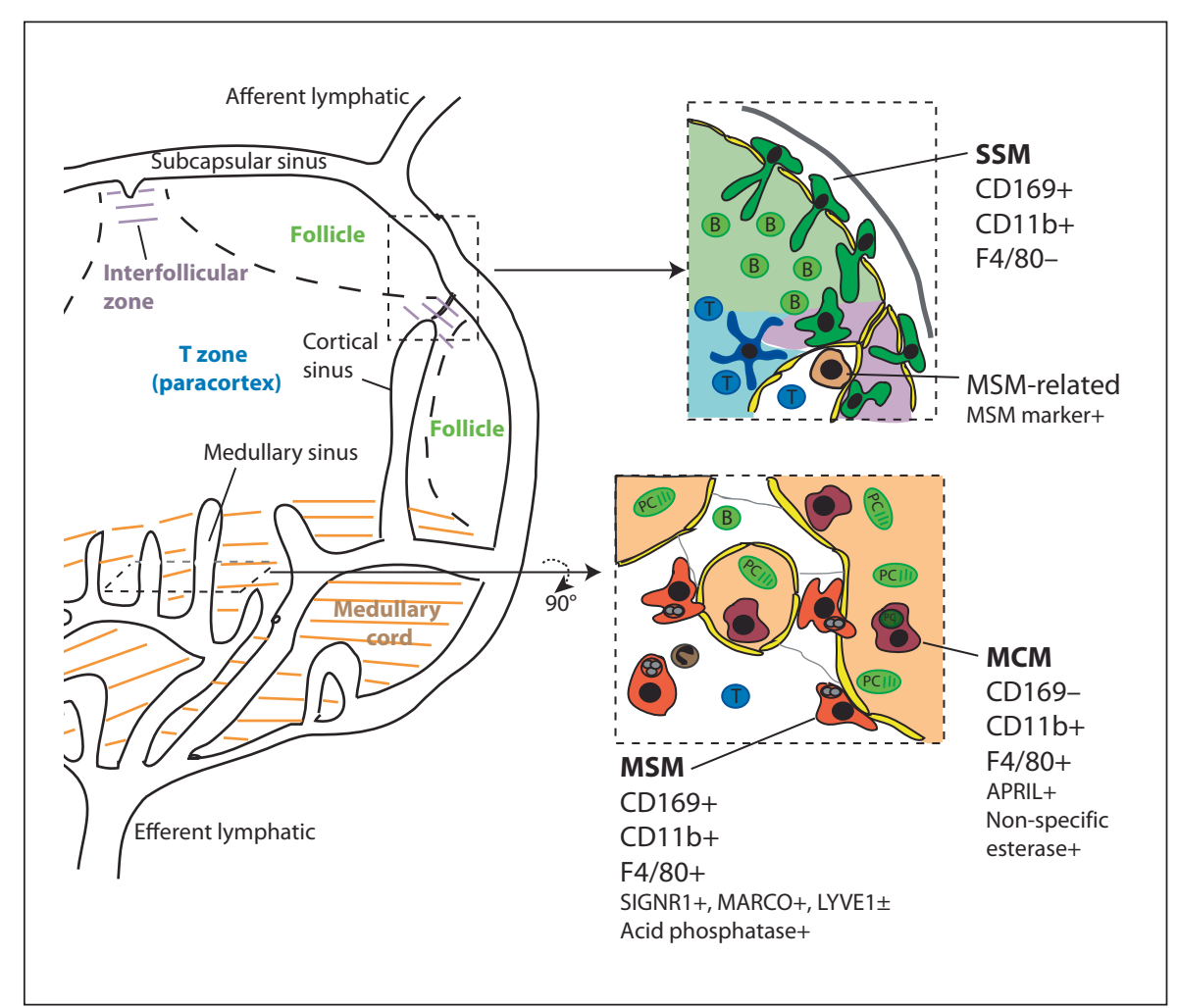

interconnected sinuses. Lymph travels from the SCS through this medullary sinus network before collecting in the efferent vessel. The tissue between the medullary sinuses, which often appears cylindrical in cross-section, is referred to as medullary cords (fig. 1). LNs in humans are considerably larger than in the mouse and rat, and trabecular sinuses radiate from the SCS through the parenchyma to the medullary sinuses, providing an additional path for lymph flow $[4,5]$.

LN macrophages have long been recognized based on their sinus-associated location and early uptake of lymphborne antigens. Early anatomical studies led to the description of macrophages in the floor of the SCS, overlying follicles, that were quick to capture small amounts of lymph-borne substances but appeared poorly phagocytic [6-8]. The macrophages associated with the medullary sinuses, by contrast, acquired large amounts of material that was readily observable within phagolysosomes [710]. The properties of these two types of sinus-associated macrophages will be discussed in detail below. The medulla also contains macrophages that reside outside the sinuses, situated within the medullary cords. Another macrophage type present in reactive LNs, though not unique to these organs, is the tingible body macrophage, which has a specialized role in the uptake of apoptotic cells within germinal centers.

Just as LNs filter lymph, the spleen filters blood. Terminal arterioles in the spleen release blood into a macrophage-lined space termed the marginal sinus. Two major types of macrophages are associated with this region: marginal metallophilic macrophages (MMMs) and marginal zone macrophages (MZMs) [11]. These cells share a number of properties with the sinus-associated LN macrophages [12], and insights that have been made through studies in the spleen that are likely to apply to LN macrophages will be discussed.

Surface phenotyping with monoclonal antibodies has been an important approach in identifying and characterizing macrophage subsets. Perhaps the best-defined marker that is present on many macrophage types is the integrin Mac1 [also known as $\alpha \mathrm{M} / \beta 2$, CD11b/CD18 or complement receptor (CR) 3] [1]. Mac1 is present on a variety of other immune cell types, for example being abundant on granulocytes, dendritic cells (DCs) and subsets of B cells. Two other markers, CD169 and F4/80, have also proved valuable in studying macrophage subsets.

CD169, also known as sialoadhesin or Siglec-1, is the largest member of the sialic acid-binding lectin (Siglec) 
family [13]. It is present on resident bone marrow macrophages, LN SCS and medullary macrophages and splenic MMMs as well as subsets of macrophages in non-lymphoid tissues, and it may be induced on monocytes under some inflammatory conditions $[12,13]$. It binds a number of heavily O-glycosylated proteins including CD43 and Mucin-1 [13]. Sialic acid-independent interactions occur with the cysteine-rich domain of the mannose receptor (MR) and with MGL1 (macrophage galactose-type Nacetylgalactosamine-specific lectin-1) $[13,14]$.

F4/80 (EMR1) is a member of the EGF-7TM family of leukocyte heptahelical molecules [15]. While it has served as an excellent marker for identifying subsets of macrophages, its function is still largely obscure [15]. It is present on a wide range of macrophage types, including LN medullary macrophages, splenic red pulp macrophages, bone marrow macrophages, sinusoidal macrophages in the liver (Kupffer cells) and on extravascular macrophages in tissues, including microglia; it is dim on inflammatory monocytes and some DCs and can be expressed on eosinophils [15].

In this review, we discuss the current understanding regarding the major macrophage types uniquely present in LNs. We refer to the macrophage subsets from an anatomical perspective as these cells have limited motility and their positioning is tightly linked to their function. One major type of macrophages has been described in the SCS, and these cells are referred to as SCS macrophages (SSMs). In an effort to simplify what can otherwise be a complex (and difficult to remember) surface markerbased nomenclature, and to highlight what we argue will be an important sub-classification of medullary macrophages, we refer to medullary sinus macrophages as MSMs and medullary cord macrophages as MCMs.

\section{Subcapsular Sinus Macrophages}

SSMs in rodents stud the lymphatic lining that overlies $B$ cell follicles, forming a dense cellular sheet [16-19]. In the mouse, they are $\mathrm{CD} 169^{\mathrm{hi}}$, $\mathrm{Macl}^{+}$and lack expression of F4/80 [17-20]. Many SSMs have a 'head' that projects into the sinus and long 'tail' processes that extend into the underlying follicle, with the 'neck' tightly inserted across the lymphatic lining cell layer (fig. 1). Real-time imaging shows these cells to be resident in this transcellular position and, in contrast to the dendrites of DCs, their long tail processes are rather stable, perhaps attached to the extracellular matrix [17-20]. The cues promoting their positioning are not defined, but lymph-derived factors seem likely to be involved since occlusion of afferent lymphatics leads to their movement into the follicle and disappearance [21, 22]. Early studies of SSMs in rodents highlighted their ability to acquire various antigens including ferritin, colloidal carbon, liposomes and opsonized antigens. Comparisons of unimmunized and passively immunized animals showed that opsonization greatly increased antigen capture by SSMs [7, 23]. Electron-microscopic studies suggested the cells have a low rate of opsonized antigen internalization and degradation $[23,24]$. Their slower rate of ablation by clodronateloaded liposomes (CLLs) than medullary macrophages supports this view [10]. Further support for the idea that SSMs retain complexes on their surface came from realtime imaging experiments where phycoerythrin immune complexes appeared to move along the surface of cell processes into follicles [20]. However, the resolution of these imaging experiments did not rule out the possibility that complexes are taken into early endosomes and recycled to the cell surface [25].

In early studies, SSMs were suggested to be involved in antigen capture and transfer to B-cell follicles [23]. This process was directly visualized using 2-photon microscopy [17-19]. SSMs were able to capture lymph-borne viruses, antigen-loaded $200-\mathrm{nm}$ beads and immune complexes via their 'heads' and to translocate and display these particles on their 'tails' for encounter by follicular B cells. Follicular B cells migrate through the dense mat of tail processes as they conduct their 'random walk' through the follicle, often making close contact with the macrophages. Cognate B cells acquired antigen directly from the macrophages via their B-cell receptor [17-19]. In the case of opsonized antigens, non-cognate B cells also acquired them via their CRs (CR1 and CR2) and facilitated their delivery to follicular DCs $[18,20]$. The complexes often appeared to be in clumps on the SSM tails and could be acquired in large units by B cells. Whether additional macrophage molecules contribute to the interaction between $\mathrm{B}$ cells and macrophages during antigen capture or transfer is not known. However, it is notable that SSMs express ICAM1 and VCAM1 [19], molecules that can facilitate integrin enhancement of antigen gathering by cognate B cells [26]. It is also notable that lymphocytes can adhere to SSMs in tissue sections [27] hinting at the existence of additional surface molecule interactions between SSMs and lymphocytes.

Although the capacity of the SSM to capture a variety of lymph-borne antigens is well established, the receptors involved are less clear, perhaps because there is often redundancy in the requirements for binding macromolecu- 
a

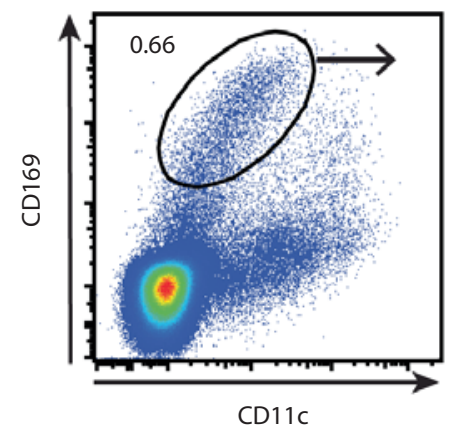

b

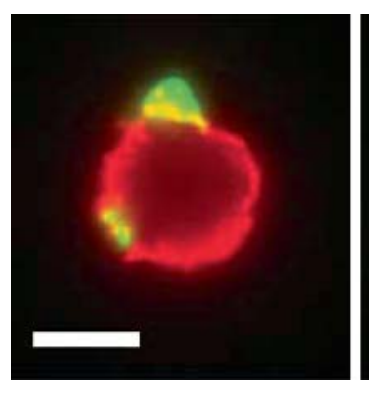

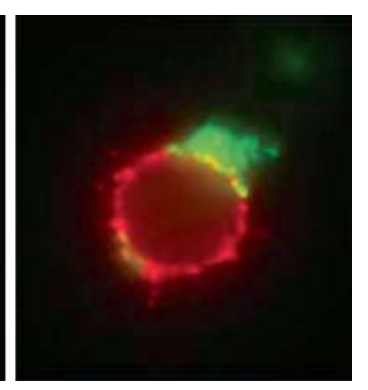

Fig. 2. $\mathrm{CD} 169^{+}$macrophage-derived blebs are acquired by lymphocytes. a LN cells prepared by enzymatic digestion [20] were stained for CD169 and CD11c and the frequency of CD169+CD11 ${ }^{\text {lo }}$ cells is shown. $\mathbf{b}$ LN cells stained for CD169, B220 and IL7R $\alpha$ were FACS sorted for the intensity of CD169 staining shown in a, positive staining for IL7R $\alpha$, and lack of B220 staining. Image shows examples of sorted cells examined by immunofluorescence microscopy to detect CD169 (green) and IL7R $\alpha$ (red).

lar complexes. SSMs express CR3 [19, 20, 28], and this receptor likely participates in the capture of opsonized antigens, though loss of this receptor ligand system alone may not prevent their capture [19; unpubl. obs.]. CD169 can bind appropriately sialylated antigens, and CD169 expressed by SSMs is also a ligand for the MR $[12,13]$. MR can be released in soluble form and may facilitate SSM binding of mannose-rich antigens [29]. Perhaps consistent with endogenous capture of soluble MR, some reports have described variable MR staining on SSMs [5, 30, 31] despite the absence of detectable mRNA expression by in situ hybridization [32]. Chicken egg-grown influenza virus bound to SSMs in a mannose-binding lectin (MBL)dependent manner [33]. Since MBL activates the complement cascade, this binding could involve CRs but might also indicate the presence of MBL receptors.

In an effort to study the cell biology of these unusual macrophages, several groups have attempted their isolation by LN digestion and cell sorting [19, 20, 34-37]. Cells that were $\mathrm{CD} 11 \mathrm{~b}^{\mathrm{hi}} \mathrm{CD} 169^{\mathrm{hi}} \mathrm{F} 4 / 80^{-} \mathrm{CD} 11 c^{\text {lo }}$ were identified and studied [20]. When taken from mice that had been immunized with phycoerythrin immune complexes these cells were phycoerythrin-labeled and perturbations that increased or decreased the number of SSMs in sections caused a corresponding increase or decrease in $\mathrm{CD} 11 \mathrm{~b}^{\mathrm{hi}} \mathrm{CD} 169^{\mathrm{hi}} \mathrm{F} 4 / 80^{-} \mathrm{CD} 11 \mathrm{c}^{\mathrm{lo}}$ cell frequencies in LN cell suspensions [20]. However, in continued efforts to characterize these cells, we have found that the purity of this population can be variable and sometimes very low; instead, the majority of cells staining for these markers are often lymphocytes that have acquired large macrophage-derived blebs (fig. 2) [unpubl. obs.]. These blebs carry all the markers associated with SSMs, thus causing the attached cells to masquerade as SSMs during flow-cytometric analysis. The lymphocytes capturing the blebs are not a random sampling of LN lymphocytes but are enriched for CD4 and CD8 double-negative, IL7R $\alpha^{\text {hi }} \mathrm{T}$ cells and natural killer (NK) cells, and in situ assessments indicate that cells of these types are often enriched near $\mathrm{CD} 169^{+}$macrophages [38; in preparation]. It seems possible that some of the $\mathrm{CD} 169^{+} \mathrm{CD} 11 \mathrm{c}^{\text {hi }}$ cells that have been detected by flow cytometry [36] may be DCs that have captured $\mathrm{CD} 169^{+}$macrophage blebs, given the limited evidence for cells expressing high amounts of both markers in tissue sections. We are continuing to investigate whether lymphocytes acquire macrophage blebs in vivo or during the process of tissue digestion and isolation. Perhaps the rigid nature of the macrophage processes or their tight association with the extracellular matrix make them prone to fragmentation during tissue preparation (in contrast to DCs that may quickly retract their mobile cell processes [39] during tissue digestion). Future studies should consider whether bleb capture reflects physiological interactions of lymphocytes with SSMs and what the functional role of this interaction might be. At the time of this writing, we 
suspect that the macrophage-gated populations examined in a number of studies may be heavily contaminated by bleb-coated lymphocytes. This may account for the low levels of CD169 transcripts detected in sorted 'SSMs' [20; www.ImmGen.org] and is a consideration that must be kept in mind when analyzing gene expression data generated from such cell preparations. As in past studies that have led to the successful characterization of new cell types, it will be important in future work to routinely confirm the identity of isolated tissue macrophages using microscopy procedures to examine cell morphology and the distribution of key markers over the plasma membrane.

\section{Medullary Sinus Macrophages and Medullary Cord Macrophages}

Anatomically, medullary sinuses are irregularly shaped, fluid-containing spaces that are lined by lymphatic endothelial cells and traversed by fine reticular strands. They contain numerous MSMs, which are attached to and sometimes appearing as part of the sinus wall, as well as being attached to reticular fibers within the lumen $[4,9,24,30,40,41]$. Medullary sinuses also contain lymphocytes that are in the act of egressing the LN and small numbers of plasma cells (fig. 1). Cortical sinuses connect to medullary sinuses, and cells and lymph from the cortical sinuses flow into medullary sinuses [42]. Cortical sinuses are densely packed with egressing lymphocytes and, in contrast to the medullary sinuses, contain few if any macrophages [42]. The factors determining the different properties of these interconnected lymphatic sinuses are not known. The parenchyma between medullary sinuses corresponds to the medullary cords (fig. 1). These structures are packed with cells, predominantly plasma cells and their precursors, macrophages, some small lymphocytes and DCs, and often contain a blood vessel. The medulla can represent a small part of the LN in the resting state but becomes enlarged at the peak of the plasma cell response with a great increase in the number of short-lived plasma cells. Polymorphonuclear cells enter LNs rapidly following immunization or infection and are often found in significant numbers in LN sinuses [9, 43-45]. Perhaps the three bestdefined functions of the LN medulla are: (1) phagocytosis and clearance of pathogens and particulate antigens from the lymph; (2) supporting short-lived plasma cell survival, and (3) providing a traffic path for egressing cells (and antibody) to reach the efferent lymph.
The most abundant macrophages in the mouse medullary regions share the CD169 and Macl markers with SSMs but are also $\mathrm{F} 4 / 80^{+}[20,46]$; many are also SIGNR $1^{+}$ $[47,48], \mathrm{MARCO}^{+}[47,49], \mathrm{MR}^{+}[5,30-32]$ and LYVE1 ${ }^{+}$ $[50,51]$. Based on their abundance in stained sections, we presume cells with these marker properties are predominantly MSMs (fig. 1), though studies that combine detection of these markers with retention of the medullary sinus structure are needed to properly address this point. Studies of human LNs indicate the SIGNR1 relative, DCSIGN, and MARCO (as well as LYVE1) can be present on the sinus-lining endothelium as well as macrophages, highlighting the importance of performing adequate resolution microscopy to achieve accurate marker assignment $[5,41]$. Loss of function studies have established that SIGNR1 is the major receptor for bacterial dextrans as well as the capsular pneumococcal polysaccharide of Streptococcus pneumoniae in the spleen and it may also bind $\mathrm{Clq}$ [52]. MARCO is a member of the scavenger receptor family and can mediate binding of a range of bacteria $[53,54]$.

In the early hours following subcutaneous injection of labeled antigen, the major site of label accumulation in LNs is the medullary region. Although the sinuses and cords were not always resolved in these studies, the majority of antigen capture presumably occurred by the lymph-exposed MSMs. Based on morphological features and the amounts of labeled antigen they internalized, these cells are classified as highly active phagocytes and they have large lysosomes and heterogeneous collections of vesicles $[4,8,9]$. In contrast, work in rat LNs indicates that macrophages within the adjacent medullary cords (MCMs) have small lysosomes and homogenous vesicles [9]. This same report showed that MSMs have high acid phosphatase and low non-specific esterase activity whereas MCMs have the reciprocal enzyme activity pattern [9]; although the significance of these differences in enzyme activity is not known, they provide phenotypic evidence that these macrophages are distinct. As another distinction, MSMs are sometimes seen containing apoptotic polymorphonuclear cells such as eosinophils whereas MCMs frequently contain apoptotic plasma cells [9, 43]. Substantial plasma cell apoptosis occurs after the peak of the primary immune response with almost $10 \%$ of the plasma cells at a given moment on day 11 after immunization being apoptotic [55]. Thus, MCMs may have a specialized ability to efficiently clear these membrane-dense cells.

As well as clearing dying plasma cells, a likely nonphagocytic function of MCMs is provision of trophic sup- 
port to plasma blasts and plasma cells. Examining mouse LNs on day 8 of the response to antigen in alum, Mohr et al. [37] observed $\mathrm{CD} 169^{-} \mathrm{F} 4 / 80^{+} \mathrm{CD} 11 \mathrm{~b}^{\text {hi }}$ cells adjacent to plasma cells in the medullary region; although the structure of sinuses and cords were not always distinguishable in these sections, the close association with plasma cells suggests the macrophages were present within cords. The isolated cells had a macrophage morphology using Giemsa-Grünwald staining and were major producers of APRIL, a plasma cell survival factor [37]. The numbers of these 'MCMs' increased markedly by day 8 of the response. Whether these $\mathrm{CD} 169^{-} \mathrm{F} 4 / 80^{+}$cells correspond to the non-specific esterase-rich macrophages enriched within medullary cords in the rat needs investigation.

The extent of macrophage communication between medullary sinuses and cords is not clear though some work has suggested MSMs can be part of the sinus wall [41]. Although most particles entering the medullary sinuses are phagocytosed and degraded locally, limited amounts of antigen may enter the cords or reach the paracortex. In a mouse influenza virus vaccination model, labeled virus accumulated in the medullary region of draining LNs and some gained access to DCs in the cords, a pathway that may facilitate antigen presentation to lymphocytes [33]. Soluble protein antigens that are not efficiently captured by phagocytes may diffuse from medullary into cortical sinuses and gain access to the $\mathrm{T}$ zone [42]. T cells reaching LNs via the afferent lymph may also access the $\mathrm{T}$ zone via the medullary region [56]. T cells reaching LNs via afferent lymphatics emanating from non-lymphoid tissues are mostly of the effector or memory type [57] and this migration path may ensure they survey the medullary region for infected cells and are exposed to any locally produced inflammatory cytokines.

In human LNs, the phenotypic distinctions between SSMs and MSMs have not yet been well defined. One study has described CD14- and CD68-expressing macrophages situated in SCS and medullary locations and also distributed in the walls of the trabecular sinuses [5]. Whether these cells also express CD169 is not yet clear though another report noted the presence of CD169 on macrophages situated in a 'perifollicular sinusoidal location', possibly SSMs [58]. In contrast to mice, human SSMs as well as MSMs stained positively for DC-SIGN (CD209), the functional ortholog of SIGNR1 $[5,59]$.

Like macrophages at other sites, medullary macrophages may have a role in taking up and sensing lipids. Mesenteric LNs are exposed to high amounts of triglyceride-rich chylomicrons from dietary fat. In Angptl4-deficient mice that have defective regulation of short-chain

Lymph Node Macrophages fatty-acid generation these LNs undergo dramatic expansion and contain numerous lipid-laden macrophages, including multinucleated $\mathrm{F} 4 / 80^{+}$giant cells [60]. Whether changes in mesenteric LN macrophage inflammatory state occur during dietary changes in lipid uptake, and how such changes modulate antigen clearance and immune functions of LNs are unknown.

\section{Interfollicular Macrophages}

The areas of LN parenchyma (or cortex) between Bcell follicles show an unusually high amount of cellular heterogeneity. SSMs appear frequently to penetrate from the SCS region and to be present in interfollicular regions (fig. 1). In addition, cells with the marker characteristics of MSMs, including F4/80, SIGNR1 and MARCO, can be present, though the uniformity of marker expression may vary $[20,47,48]$. Although interfollicular regions usually contain some lymphatic sinus structure, it is often unclear whether these are blind-ended structures that allow 'pooling' of lymph from the SCS or whether they are interconnected to the medullary (or cortical) sinuses. Moreover, in some cases, depending on the orientation of the $\mathrm{LN}$ during sectioning and the proximity of the B-cell areas to the medulla, the distinction between interfollicular regions and medullary regions can be difficult to discern. Interfollicular areas contain a high frequency of B cells, $\mathrm{T}$ cells and DCs and are a major site of DC influx to the LN from the afferent lymph [56]. A further indication of their specialization is the directed movement of activated $\mathrm{B}$ and $\mathrm{T}$ cells into these regions during immune responses $[61,62]$. In the case of activated B cells, this movement is promoted by EBI2 (GPR183) and its oxysterol ligand $7 \alpha, 25$-dihydroxycholesterol $[61,63]$. It is possible that the reduced antibody responses observed in EBI2-deficient mice are a consequence of a reduced ability for activated $\mathrm{B}$ cells to interact with macrophages in interfollicular regions. Macrophages may also deliver antigens to DCs in this region to foster CD8 T-cell responses, as discussed further below. As well as interfollicular regions, LN macrophages are occasionally observed extending more deeply along the B-T boundary or into the T zone $[20,36]$.

\section{Permissivity to Infection}

LN medullary macrophages are recognized for their ability to capture, phagocytose and destroy pathogens draining from sites of infection, a process that helps pre- 
vent systemic spread [64]. Therefore, it has come as something of a surprise to learn that SSMs and their CD169+ counterparts in the spleen, MMMs, are prone to infection by a range of viruses [35, 65-68]. These observations suggest a permissivity of SSMs and MMMs for viral infection [66]. The physiological basis for and benefits of this permissivity are beginning to come to light. In the case of systemic vesicular stomatitis virus (VSV) infection, many blood-exposed macrophage types become rapidly infected. However, viral replication is only detected in the spleen and here only within MMMs [69]. Building from evidence that type I IFN receptor signaling is highly restrictive for VSV replication, Honke et al. [69] hypothesized that removing Usp18, a negative regulator of IFN $\alpha$ R1 signaling, would reduce the extent of viral replication. Consistent with their model, they found that MMMs expressed Usp18 and that viral replication in the spleen was prevented in Usp18 $8^{-/}$mice, suggesting that MMMs, and thus perhaps SSMs, depend on Usp18-mediated negative regulation of IFNR1 to sustain a viral replication permissive state. This specialized property of MMMs and SSMs may account for the apparently selective replication of other viruses within these macrophages: vaccinia virus [66] and cow pox virus [67] replicate preferentially in SSMs after subcutaneous inoculation; murine cytomegalovirus infected both SSMs in the mediastinal LN and splenic MMMs following peritoneal inoculation [67], and lymphocytic choriomeningitis virus replicated in MMMs (and possibly MZMs) in the spleen after intravenous infection [68]. In addition, dengue virus replicated in SSMs following skin infection [70] though mice lacking IFN $\alpha \mathrm{R} 1$ and IFN $\gamma \mathrm{R}$ were studied here because of the ability of the dengue virus to inhibit human but not mouse IFNR signaling; given the Usp18 findings, it would be interesting to revisit this analysis and ask whether early dengue virus replication can be detected in SSMs of wild-type mice.

The permissivity of SSMs to infection may not be limited to viruses. Subcutaneously inoculated Toxoplasma gondii preferentially infects and replicates within SSMs [45] and IFN-I inhibits T. gondii growth in monocytederived macrophages [71]. Whether other properties of SSMs (and MMMs) make them unusually permissive to infection by intracellular pathogens, such as low lysosomal activity or repression of intracellular pathogensensing pathways, remains an interesting area for future investigation. Of course, these cells are unlikely to lack all anti-pathogen defense mechanisms. Indeed, following Leishmania donovani infection, splenic MZMs and MMMs showed IRF7 recruitment to phagosomes and
IRF7 deficiency was associated with a small increase in intracellular parasite load [72]. Finally, the expression of CD4 by SSMs in rodents [9; unpubl. obs.] raises the question of whether CD4 is expressed by human SSMs and, if so, what role these cells play during HIV propagation in human LNs.

Viral replication in SSMs may augment LN immune responses in a number of ways. In the case of subcutaneous VSV infection, viral replication in SSMs was necessary for the production of sufficient IFN-I to protect intranodal nerves from infection [35]. The IFN-I appeared to come both from the SSMs and from plasmacytoid DCs that were recruited into their proximity [35]. Similarly, splenic MMMs and MZMs are the major IFN-I producers following intravenous HSV infection [73]. A second function of permissive viral replication in SSMs may be to generate intact viral particles to provoke antibody responses, since viral particles are more effective in promoting B-cell activation than free antigens [74]. In the case of systemic VSV infection, ablation of $\mathrm{CD} 169^{+}$cells by diphtheria toxin (DT) treatment of mice expressing the DT receptor in $\mathrm{CD}_{169^{+}}$cells (CD169-DTR mice), or removal of Usp18 and thus suppression of viral replication in $\mathrm{CD}_{169}{ }^{+}$cells, led to a reduced antibody (and Tcell) response [69]. However, following subcutaneous VSV infection, macrophage ablation by CLL treatment led to an augmented antibody response [35]. This different outcome might indicate that the less selective CLLbased macrophage ablation tool led to a more drastic loss of viral clearance capability, thus increasing exposure of adaptive immune cells to virus or virally induced inflammatory mediators. Future studies of the LN response to VSV in mice in which $\mathrm{CD} 169^{+}$cells have been selectively ablated may help address this discrepancy.

A third benefit of SSM viral replication permissivity may be to facilitate the development of effector CD8 Tcell responses, either directly, by presenting antigen to $\mathrm{T}$ cells, or indirectly, by antigen transfer to nearby DCs. Following subcutaneous vaccinia virus infection, $85 \%$ of the infected LN cells were $\mathrm{CD} 169^{+}$macrophages, with the majority of these being F4/80- SSMs [75]. Antigen-specific CD8 T cells accumulated in proximity to these macrophages in interfollicular regions, but most CD8 T-cell contacts were with DCs, and priming was more successful via DCs $[66,75]$. Presentation by the macrophages alone was able to stimulate some T-cell division, but was not good at generating effector CD8 T cells. One factor to keep in mind in this context was the use of DT treatment of CD11c-DTR mice to study the antigen-presenting contribution of DCs versus macrophages. Many LN macro- 
phages, as well as splenic MZMs, express sufficient amounts of CD11c to be ablated by DT treatment of CD11c-DTR mice [35, 76, 77; unpubl. obs.] and consistent with this, a $\sim 10$-fold reduction in vaccinia virus-infected macrophages was noted in the DT-treated CD11c-DTR mice [75]. Thus, the functional properties being studied following DT treatment are of the toxin-resistant fraction of macrophages. Perhaps the replication of virus in $\mathrm{CD} 69^{+}$macrophages permits subsequent infection of nearby DCs, facilitating their full activation, recruitment of CD8 T cells and antigen presentation. Further evidence for antigen transfer from sinus-associated macrophages to T-cell priming DCs comes from the finding that antibody-mediated targeting of antigen to $\mathrm{CD} 169^{+}$ MMMs in the spleen led to cross-presentation by $\mathrm{CD} 8^{+}$ DCs to achieve effective cytotoxic T-lymphocyte activation [77]. Similarly, $\mathrm{CD} 169^{+}$macrophages participated in apoptotic cell capture in the spleen but presentation to $\mathrm{T}$ cells was by neighboring $\mathrm{CD} 8{ }^{+} \mathrm{CD} 103^{+}$DCs [78]. SSMs in LNs captured subcutaneously injected apoptotic cells and when SSMs and other $\mathrm{CD} 169^{+}$cells were ablated by treating CD169-DTR mice with DT, CD8 T-cell priming against an apoptotic cell antigen failed [36]. CD11c ${ }^{\text {hi }}$ cells were involved in antigen presentation to the CD8 T cells, and we suspect that these cells acquired apoptotic cellderived antigen from SSMs or $\mathrm{CD} 169^{+}$interfollicular macrophages [36]. This study suggests a further mechanism by which SSMs might contribute to anti-viral CD8 T-cell responses is by capturing apoptotic cells or cell debris draining to LNs from infected tissues and making viral antigen available for the subsequent priming of CD8 T-cell responses.

During the splenic response to lymphocytic choriomeningitis virus, there was marked upregulation of CXCR3 ligands in the MZ, likely made by MMMs, and CXCR3-mediated guidance of CD8 T cells to the MZ was critical for generation of short-term effector cells [68]. These data suggested that recruitment of cognate T cells into the region of high viral antigen density is important for generating short-term effector cells. Although the study did not determine whether the macrophages were directly involved in antigen presentation to the CD8 T cells or whether a DC intermediary was involved, it seems likely that the CXCR3 receptor-ligand system will operate along with the CCR5 receptor-ligand system [75] during LN macrophage infections that result in effector CD8 T-cell recruitment and activation.

The ability of infected SSMs to present antigens in the context of MHC class I is indicated by their ability to be killed by CD8 cells during Toxoplasma infection [79].
However, whether they express sufficient amounts of costimulatory molecules to support naïve T-cell priming is less clear, and most studies to date suggest they are not well equipped for this function, though they are apparently competent to promote activation of the effector type iNKT cell [80].

The ability of SSMs to present CD1d-restricted lipid antigens to iNKT cells was tested by immunizing mice with 200-nm silica microspheres coated with $\alpha$ GalCercontaining liposomes [80]. These particles colocalized with CD169-staining cells in mediastinal LNs $2 \mathrm{~h}$ after intraperitoneal immunization and real-time imaging showed that iNKT cells made increased numbers of contacts with SSMs $6 \mathrm{~h}$ after antigen administration. Depletion of macrophages (but not DCs or B cells) using CLLs led to loss of iNKT cell activation. Given that lipid loading on CD1d is thought to require passage through endocytic compartments, these data suggest that SSMs internalized some of the lipid. However, whether the cells actively phagocytose the $200-\mathrm{nm}$ microspheres or instead absorb some of the surface-displayed liposomes remains to be assessed. Recent evidence has highlighted the importance of CD1d presentation of the endogenous lipid $\beta G l c C e r$ and provides evidence that upregulation of lipid presentation occurs following exposure to innate stimuli such as lipopolysaccharides [81]. Given the ability of SSMs to bind lymph-borne lipopolysaccharides [82], endogenous lipid presentation may be another pathway of SSM-mediated iNKT cell activation.

\section{LN Macrophage Development}

To fully understand LN macrophage heterogeneity and to be able to genetically probe LN macrophage functions it is necessary to characterize their development. The developmental pathways of different tissue macrophage types are only now beginning to be elucidated [3]. In mice lacking CSF1 (op/op mice), there is a loss of $\mathrm{CD}_{169^{+}}$SSMs (as well as splenic MMMs and MZMs) whereas medullary $\mathrm{F} 4 / 80^{+}$cells are retained $[83,84]$. The CSF1 dependence of SSMs confirms their macrophage identity [3]. A second key cytokine requirement for SSMs (as well as splenic MMMs and MZMs) is lymphotoxin (LT) $\alpha_{1} \beta_{2}[20,85,86]$. Although mice lacking this TNF family member or its receptor, LT $\beta R$, lack most or all LNs, the role of LT $\beta R$ signaling in LNs can be studied by treating mice with the soluble antagonist, LT $\beta R-I g$ [87]. Bockade of LT $\beta R$ signaling for 4 weeks caused a marked decrease in $\mathrm{CD} 169^{+} \mathrm{F} 4 / 80^{-}$cell abundance in $\mathrm{LN}$ sections 
and a reduction in CD169-staining cells detected by flow cytometry [20]. While the latter analysis suffers from contamination of the gated populations by macrophagebleb-coated lymphocytes, it appears that the number of bleb-coated cells decreases in proportion with the decrease in macrophage frequency. B cells were a necessary source of $L T \alpha_{1} \beta_{2}$ for development and/or maintenance of a normal SSM population [20] as they are for MMMs and MZMs [86]. LT $\beta R$ signals via nuclear factor (NF) $\kappa B$ transcription factors and hematopoietic cell deficiency in $\mathrm{NF \kappa B}$ p52 causes deficiencies in splenic $\mathrm{CD} 169^{+}$macrophages [88]; the role of $\mathrm{NF \kappa B}$ transcription factors in LN macrophages has not yet been reported. TNF also contributes to MMM and MZM development/maintenance, though more weakly than LT $\beta$, whereas it may not be required for $\mathrm{LN}$ macrophage homeostasis [89]. $\mathrm{LT} \alpha_{1} \beta_{2}$ levels in LNs under homeostatic conditions are limiting for SSM induction or maintenance as mice that transgenically overexpress $\mathrm{LT} \alpha_{1} \beta_{2}$ on B cells have a thicker layer of SSMs and greater frequencies of CD169-staining cells in flow cytometry [20]. It seems likely that the $\mathrm{LT} \alpha_{1} \beta_{2}$ dependence of SSMs serves as a mechanism to achieve homeostasis between the size of the B-cell follicle, which can grow rapidly during immune responses, and the surface coverage by SSMs. Following ablation by CLL treatment, SSMs and MSMs took several months to be replenished [10]. However, when the cells were more selectively ablated by DT treatment of CD169-DTR mice, there was substantial reconstitution within 10 days [36]. Similarly, when MMMs were ablated by DT treatment of CD11c-DTR or CD169-DTR mice, they reappeared in significant numbers by day $10[76,78]$. It seems possible that the slow rate of SSM replacement in mice treated with CLL reflects a long-lasting effect of this macrophage toxin. $\mathrm{CD}_{169^{+}} \mathrm{LN}$ macrophages were replaced efficiently $(>80 \%)$ by bone marrow-derived cells in radiation chimeras, confirming their bone marrow origin [20].

The requirements for MSM and MCM development are less well understood than for SSMs. F4 $/ 80^{+}$macrophages were retained in the medullary region of mice following a month of LT blockade [20] and CSF1-deficient mice also retained $\mathrm{F} 4 / 80^{+}$cells $[83,84]$. Whether the $\mathrm{F} 4 / 80^{+} \mathrm{CD} 169^{+}$('MSM') and $\mathrm{F} 4 / 80^{+} \mathrm{CD} 169^{-}$('MCM') subsets were equally retained has not yet been investigated. Recent studies have indicated that CSF1R deficiency causes a more penetrant loss of some macrophage types than occurs in CSF1-deficient mice, the difference likely reflecting the activity of IL34 as a second CSF1R ligand $[3,90]$. It will be important to determine whether medullary macrophages are more dependent on CSF1R than
CSF1. Such studies combined with lineage tracing experiments should help determine whether each LN macrophage type differentiates from a common precursor, perhaps with medullary macrophages giving rise to SSMs in a LT- and CSF1-dependent manner, or whether the cells have distinct precursors.

As noted above, there are a number of similarities between LN SSMs and splenic MMMs: both are CD169hi, depend on CSF1, B cells and $L T \alpha_{1} \beta_{2}$, are prone to viral infection and are situated at the interface of the follicle and sinus. However, there are also notable distinctions, such as the ready capture of immune complexes by SSMs but not MMMs. This may reflect anatomical differences of the tissues but could also relate to intrinsic differences in these cells that match their functions with the types of pathogens and antigens they typically encounter. In a similar way, LN MSMs and splenic MZMs share markers such as SIGNR1 and MARCO and the property of being highly phagocytic, but important differences exist such as higher CD169 expression on MSMs and lack of F4/80 expression on MZMs. The parallels between LN MCMs and macrophages in the spleen are less clear at present, but given the abundant F4/80 expression in the splenic red pulp and the role of this compartment in supporting short-lived plasma cells, it seems likely that there will be an MCM-related subset of red pulp macrophages. We anticipate that the related subsets of LN and splenic macrophages will share much of their developmental program but that differences in the final maturation signals will specify fates unique to their tissue of residence.

\section{Conclusion}

Recent studies in rodents have led to advances in the understanding of SSMs, including their function in antigen capture, translocation and display to $\mathrm{B}$ cells, their permissivity to pathogen replication and their roles in CD8 T-cell and iNKT cell responses. Advances in our understanding of medullary macrophages have been more limited. The highly phagocytic MSMs mediate clearance of particulates, pathogens and dying cells from the lymph, while MCMs may support plasma cell survival and clear away their dead cells. A key challenge in further defining the differences between MSMs and MCMs will be to maintain the sinus spaces intact to allow cells within sinuses and cords to be more routinely distinguished. This should in turn facilitate improved mapping of surface markers and functional properties onto MSMs and MCMs. In humans, a more detailed comparison of SSMs 
and MSMs is also needed to determine whether these subsets have distinct properties, similar to their rodent counterparts. Generation of genetic tools that allow ablation of individual LN macrophage subsets will also help advance the field. Further work is needed to understand the macrophage complexity in interfollicular regions where SSMs, MSMs and perhaps additional macrophage types comingle and crosstalk with DCs and lymphocytes.

Sinus lining lymphatic endothelium in LNs expresses endocytic receptors $[41,91]$ and can take up a variety of materials, sometimes in large amounts. For example, silica-coated iron oxide nanoparticles were preferentially taken up by LYVE1 ${ }^{+}$SCS lining cells rather than macrophages [92] and viral particles have been found in medullary sinus-lining cells [19]. Future work needs to explore how sinus-lining endothelial cells and the closely associated macrophages interact and share their antigen handling and barrier functions.

While this review has attempted to emphasize general themes in LN macrophage biology, it is likely that important differences exist between macrophages in LNs draining different tissue beds. One indication of this is provided by the lipid accumulation in mesenteric LN macrophages of angptl4-deficient mice. Another may be the 'firewall' function of mesenteric LNs in preventing commensal bacteria that breach the intestinal epithelial bar- rier from reaching the systemic circulation [93]. We can anticipate that just as stromal cells, endothelial cells and DCs from peripheral and mucosal LNs differ, so will key aspects of macrophage phenotype and function. This may be as a consequence of different factors flowing to the LN in the lymph but may also reflect local morphogenic differences within the LN. Moreover, although macrophages do not have the remarkable migratory behavior of DCs, there are some conditions such as during solid tumor growth where considerable numbers of tissue macrophages may reach and modify draining LNs.

To properly characterize LN macrophages, and their relatives in the spleen, improved procedures for their isolation to high purity are needed. Methods that allow their culture will also greatly enhance their study. New insights into their biology are also likely to emerge from a more complete assessment of their developmental pathway(s) and relationships to other macrophage populations in the body.

\section{Acknowledgments}

We thank Tri Phan and Cliff Lowell for helpful discussions and comments on the manuscript. Work from the Cyster laboratory discussed in this review was supported in part by NIH grant AI45073.

\section{References}

1 Gordon S, Taylor PR: Monocyte and macrophage heterogeneity. Nat Rev Immunol 2005;5:953-964.

2 Gordon S: The macrophage: past, present and future. Eur J Immunol 2007;37(suppl 1):S9-S17.

3 Hashimoto D, Miller J, Merad M: Dendritic cell and macrophage heterogeneity in vivo. Immunity 2011;35:323-335.

4 Young B, Heath JW: Wheater's Functional Histology, ed 4. Edinburgh, Churchill Livingstone, 2000.

5 Angel CE, Chen CJ, Horlacher OC, Winkler S, John T, Browning J, MacGregor D, Cebon J, Dunbar PR: Distinctive localization of antigen-presenting cells in human lymph nodes. Blood 2009;113:1257-1267.

6 Clark SL: The reticulum of lymph nodes in mice studied with the electron microscope. Am J Anat 1962;110:217-257.

7 Nossal GJ, Ada GL, Austin CM, Pye J: Antigens in immunity. 8. Localization of 125-Ilabelled antigens in the secondary response. Immunology 1965;9:349-357.
8 Fossum S: The architecture of rat lymph nodes. IV. Distribution of ferritin and colloidal carbon in the draining lymph nodes after foot-pad injection. Scand J Immunol 1980; 12:433-441.

-9 Steer HW, Foot RA: Changes in the medulla of the parathymic lymph nodes of the rat during acute gastro-intestinal inflammation. J Anat 1987;152:23-36.

10 Delemarre FG, Kors N, Kraal G, van Rooijen $\mathrm{N}$ : Repopulation of macrophages in popliteal lymph nodes of mice after liposome-mediated depletion. J Leukoc Biol 1990;47:251-257.

11 Kraal G, Mebius R: New insights into the cell biology of the marginal zone of the spleen. Int Rev Cytol 2006;250:175-215.

12 Martinez-Pomares L, Gordon S: CD169(+) macrophages at the crossroads of antigen presentation. Trends Immunol 2012;33:6670.

13 Crocker PR, Paulson JC, Varki A: Siglecs and their roles in the immune system. Nat Rev Immunol 2007;7:255-266.
4 Kumamoto Y, Higashi N, Denda-Nagai K, Tsuiji M, Sato K, Crocker PR, Irimura T: Identification of sialoadhesin as a dominant lymph node counter-receptor for mouse macrophage galactose-type C-type lectin 1. J Biol Chem 2004;279:49274-49280.

15 Gordon S, Hamann J, Lin HH, Stacey M: F4/80 and the related adhesion-GPCRS. Eur J Immunol 2011;41:2472-2476.

16 Farr AG, Cho Y, De Bruyn PP: The structure of the sinus wall of the lymph node relative to its endocytic properties and transmural cell passage. Am J Anat 1980;157:265-284.

17 Carrasco YR, Batista FD: B cells acquire particulate antigen in a macrophage-rich area at the boundary between the follicle and the subcapsular sinus of the lymph node. Immunity 2007;27:160-171.

18 Phan TG, Grigorova I, Okada T, Cyster JG: Subcapsular encounter and complement-dependent transport of immune complexes by lymph node B cells. Nat Immunol 2007;8: 992-1000. 
19 Junt T, Moseman EA, Iannacone M, Massberg S, Lang PA, Boes M, Fink K, Henrickson SE, Shayakhmetov DM, Di Paolo NC, van Rooijen N, Mempel TR, Whelan SP, von Andrian UH: Subcapsular sinus macrophages in lymph nodes clear lymph-borne viruses and present them to antiviral B cells. Nature 2007;450:110-114.

20 Phan TG, Green JA, Gray EE, Xu Y, Cyster JG: Immune complex relay by subcapsular sinus macrophages and noncognate B cells drives antibody affinity maturation. Nat Immunol 2009;10:786-793.

-21 Mebius RE, Hendriks HR, Breve J, Kraal G: Macrophages and the activity of high endothelial venules. the effect of interferon-gamma. Eur J Immunol 1990;20:1615-1618.

-22 Mebius RE, Streeter PR, Breve J, Duijvestijn AM, Kraal G: The influence of afferent lymphatic vessel interruption on vascular addressin expression. J Cell Biol 1991;115:8595.

23 Szakal AK, Holmes KL, Tew JG: Transport of immune complexes from the subcapsular sinus to lymph node follicles on the surface of nonphagocytic cells, including cells with dendritic morphology. J Immunol 1983;131: 1714-1727.

24 Fossum S, Vaaland JL: The architecture of rat lymph nodes. I. Combined light and electron microscopy of lymph node cell types. Anat Embryol (Berl) 1983;167:229-246.

25 Cyster JG: B cell follicles and antigen encounters of the third kind. Nat Immunol 2010;11:989-996.

-26 Fleire SJ, Goldman JP, Carrasco YR, Weber M, Bray D, Batista FD: B cell ligand discrimination through a spreading and contraction response. Science 2006;312:738-741.

-27 van den Berg TK, Breve JJ, Damoiseaux JG, Dopp EA, Kelm S, Crocker PR, Dijkstra CD, Kraal G: Sialoadhesin on macrophages: Its identification as a lymphocyte adhesion molecule. J Exp Med 1992;176:647-655.

28 Witmer MD, Steinman RM: The anatomy of peripheral lymphoid organs with emphasis on accessory cells: Light-microscopic immunocytochemical studies of mouse spleen, lymph node, and Peyer's patch. Am J Anat 1984; 170:465-481.

-29 Taylor PR, Zamze S, Stillion RJ, Wong SY, Gordon S, Martinez-Pomares L: Development of a specific system for targeting protein to metallophilic macrophages. Proc Natl Acad Sci USA 2004;101:1963-1968.

- 30 Takahashi K, Donovan MJ, Rogers RA, Ezekowitz RA: Distribution of murine mannose receptor expression from early embryogenesis through to adulthood. Cell Tissue Res 1998;292:311-323.

- 31 McKenzie EJ, Taylor PR, Stillion RJ, Lucas AD, Harris J, Gordon S, Martinez-Pomares L: Mannose receptor expression and function define a new population of murine dendritic cells. J Immunol 2007;178:4975-4983.
32 Linehan SA, Martinez-Pomares L, Stahl PD, Gordon S: Mannose receptor and its putative ligands in normal murine lymphoid and nonlymphoid organs: in situ expression of mannose receptor by selected macrophages, endothelial cells, perivascular microglia, and mesangial cells, but not dendritic cells. J Exp Med 1999;189:1961-1972.

33 Gonzalez SF, Lukacs-Kornek V, Kuligowski MP, Pitcher LA, Degn SE, Kim YA, Cloninger MJ, Martinez-Pomares L, Gordon S, Turley SJ, Carroll MC: Capture of influenza by medullary dendritic cells via SIGN-R1 is essential for humoral immunity in draining lymph nodes. Nat Immunol 2010;11:427434.

-34 Barral P, Polzella P, Bruckbauer A, van Rooijen N, Besra GS, Cerundolo V, Batista FD: CD169(+) macrophages present lipid antigens to mediate early activation of iNKT cells in lymph nodes. Nat Immunol 2010;11: 303-312.

35 Iannacone M, Moseman EA, Tonti E, Bosurgi L, Junt T, Henrickson SE, Whelan SP, Guidotti LG, von Andrian UH: Subcapsular sinus macrophages prevent CNS invasion on peripheral infection with a neurotropic virus. Nature 2010;465:1079-1083.

36 Asano K, Nabeyama A, Miyake Y, Qiu CH, Kurita A, Tomura M, Kanagawa O, Fujii SI, Tanaka M: CD169-positive macrophages dominate antitumor immunity by crosspresenting dead cell-associated antigens. Immunity 2010;34:85-95.

-37 Mohr E, Serre K, Manz RA, Cunningham AF, Khan M, Hardie DL, Bird R, MacLennan IC: Dendritic cells and monocyte/macrophages that create the IL-6/APRIL-rich lymph node microenvironments where plasmablasts mature. J Immunol 2009;182:21132123.

38 Gray EE, Suzuki K, Cyster JG: Cutting edge: Identification of a motile IL-17-producing $\gamma \delta \mathrm{T}$ cell population in the dermis. J Immunol 2011;186:6091-6095.

39 Miller MJ, Hejazi AS, Wei SH, Cahalan MD, Parker I: T cell repertoire scanning is promoted by dynamic dendritic cell behavior and random $\mathrm{T}$ cell motility in the lymph node. Proc Natl Acad Sci USA 2004;101:9981003.

40 Fossum S: The architecture of rat lymph nodes. II. Lymph node compartments. Scand J Immunol 1980;12:411-420.

-41 Martens JH, Kzhyshkowska J, FalkowskiHansen M, Schledzewski K, Gratchev A, Mansmann U, Schmuttermaier C, Dippel E, Koenen W, Riedel F, Sankala M, Tryggvason K, Kobzik L, Moldenhauer G, Arnold B, Goerdt S: Differential expression of a gene signature for scavenger/lectin receptors by endothelial cells and macrophages in human lymph node sinuses, the primary sites of regional metastasis. J Pathol 2006;208:574589.
42 Grigorova IL, Panteleev M, Cyster JG: Lymph node cortical sinus organization and relationship to lymphocyte egress dynamics and antigen exposure. Proc Natl Acad Sci USA 2010;107:20447-20452.

43 Nossal GJ, Abbot A, Mitchell J: Antigens in immunity. XIV. Electron microscopic radioautographic studies of antigen capture in the lymph node medulla. J Exp Med 1968;127: 263-276.

44 Yang CW, Strong BS, Miller MJ, Unanue ER: Neutrophils influence the level of antigen presentation during the immune response to protein antigens in adjuvants. J Immunol 2010;185:2927-2934.

-45 Chtanova T, Schaeffer M, Han SJ, van Dooren GG, Nollmann M, Herzmark P, Chan SW, Satija H, Camfield K, Aaron H, Striepen B, Robey EA: Dynamics of neutrophil migration in lymph nodes during infection. Immunity 2008;29:487-496.

-46 Hume DA, Robinson AP, MacPherson GG, Gordon S: The mononuclear phagocyte system of the mouse defined by immunohistochemical localization of antigen F4/80. Relationship between macrophages, Langerhans cells, reticular cells, and dendritic cells in lymphoid and hematopoietic organs. J Exp Med 1983;158:1522-1536.

47 Kang YS, Yamazaki S, Iyoda T, Pack M, Bruening SA, Kim JY, Takahara K, Inaba K, Steinman RM, Park CG: SIGN-R1, a novel C-type lectin expressed by marginal zone macrophages in spleen, mediates uptake of the polysaccharide dextran. Int Immunol 2003;15:177-186.

48 Geijtenbeek TB, Groot PC, Nolte MA, van Vliet SJ, Gangaram-Panday ST, van Duijnhoven GC, Kraal G, van Oosterhout AJ, van Kooyk Y: Marginal zone macrophages express a murine homologue of DC-SIGN that captures blood-borne antigens in vivo. Blood 2002;100:2908-2916.

- 49 Elomaa O, Kangas M, Sahlberg C, Tuukkanen J, Sormunen R, Liakka A, Thesleff I, Kraal G, Tryggvason K: Cloning of a novel bacteria-binding receptor structurally related to scavenger receptors and expressed in a subset of macrophages. Cell 1995;80:603609.

-50 Schledzewski K, Falkowski M, Moldenhauer G, Metharom P, Kzhyshkowska J, Ganss R, Demory A, Falkowska-Hansen B, Kurzen H, Ugurel S, Geginat G, Arnold B, Goerdt S: Lymphatic endothelium-specific hyaluronan receptor LYVE-1 is expressed by stabilin-1+, F4/80+, CD11b+ macrophages in malignant tumours and wound healing tissue in vivo and in bone marrow cultures in vitro: implications for the assessment of lymphangiogenesis. J Pathol 2006;209:67-77.

51 Grigorova IL, Schwab SR, Phan TG, Pham TH, Okada T, Cyster JG: Cortical sinus probing, S1P1-dependent entry and flow-based capture of egressing $\mathrm{T}$ cells. Nat Immunol 2009;10:58-65. 
52 Kang YS, Do Y, Lee HK, Park SH, Cheong C, Lynch RM, Loeffler JM, Steinman RM, Park CG: A dominant complement fixation pathway for pneumococcal polysaccharides initiated by SIGN-R1 interacting with C1q. Cell 2006; 125:47-58.

53 van der Laan LJ, Dopp EA, Haworth R, Pikkarainen T, Kangas M, Elomaa O, Dijkstra CD, Gordon S, Tryggvason K, Kraal G: Regulation and functional involvement of macrophage scavenger receptor MARCO in clearance of bacteria in vivo. J Immunol 1999;162:939-947.

54 Areschoug T, Gordon S: Scavenger receptors: role in innate immunity and microbial pathogenesis. Cell Microbiol 2009;11:11601169.

-55 Smith KGC, Hewitson TD, Nossal GJV, Tarlinton DM: The phenotype and fate of the antibody-forming cells of the splenic foci. Eur J Immunol 1996;26:444-448.

- 56 Braun A, Worbs T, Moschovakis GL, Halle S, Hoffmann K, Bolter J, Munk A, Forster R: Afferent lymph-derived Tcells and DCs use different chemokine receptor CCR7-dependent routes for entry into the lymph node and intranodal migration. Nat Immunol 2011;12:879-887.

57 Mackay CR, Marston WL, Dudler L: Naive and memory $\mathrm{T}$ cells show distinct pathways of lymphocyte recirculation. J Exp Med 1990;171:801-817.

58 Hartnell A, Steel J, Turley H, Jones M, Jackson DG, Crocker PR: Characterization of human sialoadhesin, a sialic acid binding receptor expressed by resident and inflammatory macrophage populations. Blood 2001; 97:288-296.

-59 Granelli-Piperno A, Pritsker A, Pack M, Shimeliovich I, Arrighi JF, Park CG, Trumpfheller C, Piguet V, Moran TM, Steinman RM: Dendritic cell-specific intercellular adhesion molecule 3-grabbing nonintegrin/ CD209 is abundant on macrophages in the normal human lymph node and is not required for dendritic cell stimulation of the mixed leukocyte reaction. J Immunol 2005; 175:4265-4273.

-60 Lichtenstein L, Mattijssen F, de Wit NJ, Georgiadi A, Hooiveld GJ, van der Meer R, He Y, Qi L, Koster A, Tamsma JT, Tan NS, Muller M, Kersten S: Angptl4 protects against severe proinflammatory effects of saturated fat by inhibiting fatty acid uptake into mesenteric lymph node macrophages. Cell Metab 2010;12:580-592.

61 Pereira JP, Kelly LM, Cyster JG: Finding the right niche: $\mathrm{B}$ cell migration in the early phases of T-dependent antibody responses. Int Immunol 2010;22:413-419.

-62 Kerfoot SM, Yaari G, Patel JR, Johnson KL, Gonzalez DG, Kleinstein SH, Haberman AM: Germinal center B cell and T follicular helper cell development initiates in the interfollicular zone. Immunity 2011;34:947-960.
63 Hannedouche S, Zhang J, Yi T, Shen W, Nguyen D, Pereira JP, Guerini D, Gaumgarten BU, Roog S, Wen B, Knochenmuss R, Moel S, Gessier F, Kelly LM, Vanek M, Laurent S, Preuss I, Miault C, Christen I, Karuna R, Li W, Koo D-I, Suply T, Schmedt C, Peters EC, Flachetto R, Kataopodis A, Spanka C, Roy M-O, Detheux M, Chen YA, Schultz PG, Cho CY, Seuwen K, Cyster JG, Sailer AW: Oxysterols direct immune cell migration through EBI2. Nature 2011;475:524-527.

64 Phan TG, Gray EE, Cyster JG: The microanatomy of B cell activation. Curr Opin Immunol 2009;21:258-265.

65 Norbury CC, Malide D, Gibbs JS, Bennink JR, Yewdell JW: Visualizing priming of virus-specific $\mathrm{CD} 8+\mathrm{T}$ cells by infected dendritic cells in vivo. Nat Immunol 2002;3: 265-271.

66 Hickman HD, Takeda K, Skon CN, Murray FR, Hensley SE, Loomis J, Barber GN, Bennink JR, Yewdell JW: Direct priming of antiviral CD8+ T cells in the peripheral interfollicular region of lymph nodes. Nat Immunol 2008;9:155-165.

67 Hsu KM, Pratt JR, Akers WJ, Achilefu SI, Yokoyama WM: Murine cytomegalovirus displays selective infection of cells within hours after systemic administration. J Gen Virol 2009;90:33-43.

$68 \mathrm{Hu}$ JK, Kagari T, Clingan JM, Matloubian M: Expression of chemokine receptor CXCR3 on $\mathrm{T}$ cells affects the balance between effector and memory CD8 T-cell generation. Proc Natl Acad Sci USA 2011;108:E118-E127.

- 69 Honke N, Shaabani N, Cadeddu G, Sorg UR, Zhang DE, Trilling M, Klingel K, Sauter M, Kandolf R, Gailus N, van Rooijen N, Burkart C, Baldus SE, Grusdat M, Lohning M, Hengel H, Pfeffer K, Tanaka M, Haussinger D, Recher M, Lang PA, Lang KS: Enforced viral replication activates adaptive immunity and is essential for the control of a cytopathic virus. Nat Immunol 2011;13:51-57.

70 Fink K, Ng C, Nkenfou C, Vasudevan SG, van Rooijen N, Schul W: Depletion of macrophages in mice results in higher dengue virus titers and highlights the role of macrophages for virus control. Eur J Immunol 2009;39: 2809-2821.

71 Schmitz JL, Carlin JM, Borden EC, Byrne GI: Beta interferon inhibits Toxoplasma gondii growth in human monocyte-derived macrophages. Infect Immun 1989;57:3254-3256.

72 Phillips R, Svensson M, Aziz N, Maroof A, Brown N, Beattie L, Signoret N, Kaye PM: Innate killing of Leishmania donovani by macrophages of the splenic marginal zone requires IRF-7. PLoS Pathog 2010;6:e1000813.

73 Eloranta ML, Alm GV: Splenic marginal metallophilic macrophages and marginal zone macrophages are the major interferon-alpha/beta producers in mice upon intravenous challenge with herpes simplex virus. Scand J Immunol 1999;49:391-394.
4 Bachmann MF, Rohrer UH, Kundig TM, Burki K, Hengartner H, Zinkernagel RM: The influence of antigen organization on $\mathrm{B}$ cell responsiveness. Science 1993;262:14481451.

75 Hickman HD, Li L, Reynoso GV, Rubin EJ, Skon CN, Mays JW, Gibbs J, Schwartz O, Bennink JR, Yewdell JW: Chemokines control naive CD8+ T cell selection of optimal lymph node antigen presenting cells. J Exp Med 2011;208:2511-2524.

76 Probst HC, Tschannen K, Odermatt B, Schwendener R, Zinkernagel RM, Van Den Broek M: Histological analysis of CD11cDTR/GFP mice after in vivo depletion of dendritic cells. Clin Exp Immunol 2005;141: 398-404.

-77 Backer R, Schwandt T, Greuter M, Oosting M, Jungerkes F, Tuting T, Boon L, O'Toole T, Kraal G, Limmer A, den Haan JM: Effective collaboration between marginal metallophilic macrophages and $\mathrm{CD} 8+$ dendritic cells in the generation of cytotoxic T cells. Proc Natl Acad Sci USA 2010;107:216-221.

-78 Miyake Y, Asano K, Kaise H, Uemura M, Nakayama M, Tanaka M: Critical role of macrophages in the marginal zone in the suppression of immune responses to apoptotic cell-associated antigens. J Clin Invest 2007; 117:2268-2278.

79 Chtanova T, Han SJ, Schaeffer M, van Dooren GG, Herzmark P, Striepen B, Robey EA: Dynamics of $\mathrm{T}$ cell, antigen-presenting cell, and pathogen interactions during recall responses in the lymph node. Immunity 2009; 31:342-355.

80 Barral P, Eckl-Dorna J, Harwood NE, De Santo C, Salio M, Illarionov P, Besra GS, Cerundolo V, Batista FD: B cell receptor-mediated uptake of CD1d-restricted antigen augments antibody responses by recruiting invariant NKT cell help in vivo. Proc Natl Acad Sci USA 2008; 105:8345-8350.

- 81 Brennan PJ, Tatituri RV, Brigl M, Kim EY, Tuli A, Sanderson JP, Gadola SD, Hsu FF, Besra GS, Brenner MB: Invariant natural killer $\mathrm{T}$ cells recognize lipid self antigen induced by microbial danger signals. Nat Immunol 2011;12:1202-1211.

82 Lu M, Munford RS: The transport and inactivation kinetics of bacterial lipopolysaccharide influence its immunological potency in vivo. J Immunol 2011;187:3314-3320.

83 Witmer-Pack MD, Hughes DA, Schuler G, Lawson L, McWilliam A, Inaba K, Steinman RM, Gordon S: Identification of macrophages and dendritic cells in the osteopetrotic op/op mouse. J Cell Sci 1993;104:10211029.

84 Cecchini MG, Dominguez MG, Mocci S, Wetterwald A, Felix R, Fleisch H, Chisholm O, Hofstetter W, Pollard JW, Stanley ER: Role of colony stimulating factor- 1 in the establishment and regulation of tissue macrophages during postnatal development of the mouse. Development 1994;120:1357-1372. 
85 Rennert PD, Browning JL, Mebius R, Mackay F, Hochman PS: Surface lymphotoxin alpha/beta complex is required for the development of peripheral lymphoid organs. J Exp Med 1996;184:1999-2006.

86 Tumanov AV, Grivennikov SI, Shakhov AN, Rybtsov SA, Koroleva EP, Takeda J, Nedospasov SA, Kuprash DV: Dissecting the role of lymphotoxin in lymphoid organs by conditional targeting. Immunol Rev 2003;195: 106-116.

$\$ 87$ Browning JL: Inhibition of the lymphotoxin pathway as a therapy for autoimmune disease. Immunol Rev 2008;223:202-220.
88 Poljak L, Carlson L, Cunningham K, KoscoVilbois MH, Siebenlist U: Distinct activities of p52/NF-kappa B required for proper secondary lymphoid organ microarchitecture: functions enhanced by Bcl-3. J Immunol 1999; 163:6581-6588.

89 Pasparakis M, Kousteni S, Peschon J, Kollias G: Tumor necrosis factor and the p55TNF receptor are required for optimal development of the marginal sinus and for migration of follicular dendritic cell precursors into splenic follicles. Cell Immunol 2000;201:3341.

90 MacDonald KP, Palmer JS, Cronau S, Seppanen E, Olver S, Raffelt NC, Kuns R, Pettit AR, Clouston A, Wainwright B, Branstetter D, Smith J, Paxton RJ, Cerretti DP, Bonham L, Hill GR, Hume DA: An antibody against the colony-stimulating factor 1 receptor depletes the resident subset of monocytes and tissue- and tumor-associated macrophages but does not inhibit inflammation. Blood 2010;116:3955-3963.
91 Prevo R, Banerji S, Ni J, Jackson DG: Rapid plasma membrane-endosomal trafficking of the lymph node sinus and high endothelial venule scavenger receptor/homing receptor stabilin-1 (FEEL-1/CLEVER-1). J Biol Chem 2004;279:52580-52592.

92 Bumb A, Regino CA, Egen JG, Bernardo M, Dobson PJ, Germain RN, Choyke PL, Brechbiel MW: Trafficking of a dual-modality magnetic resonance and fluorescence imaging superparamagnetic iron oxide-based nanoprobe to lymph nodes. Mol Imaging Biol 2011;13:1163-1172.

93 Macpherson AJ, Geuking MB, Slack E, Hapfelmeier S, McCoy KD: The habitat, double life, citizenship, and forgetfulness of IgA. Immunol Rev 2011;245:132-146. 